\title{
Caracterização Fisiográfica da Sub-bacia hidrográfica do riacho Bilheira, Taperuaba-CE.
}

\author{
Physiographic characterization about sub-basin of Bilheira river, Taperuaba - CE.
}

\author{
BARROS $^{1}$, R. O.; RODRIGUES ${ }^{2}$, J. M. D.; LIMA ${ }^{3}$, E. C.
}

renatooliveiratap@gmail.com

\begin{abstract}
Resumo
A presente pesquisa busca realizar uma descrição dos componentes físico-naturais, assim como identificar os principais impactos ambientais na Sub-bacia hidrográfica do riacho Bilheira, como forma de subsidiar o planejamento ambiental. A área em estudo possui uma extensão territorial de $75 \mathrm{~km}^{2}$, totalmente alocada no sistema hidrográfico do rio Aracatiaçu, onde este por sua vez está inserido na bacia hidrográfica do litoral. A área em estudo está inserida dentre os limites municipais de Sobral mais precisamente nos distritos de Taperuaba e Aracatiaçu. A metodologia consiste na descrição fisiográfica que se tratando de bacias hidrográficas como unidade de estudo, recai como imprescindível. Contudo, a pesquisa se desenvolveu por meio de um levantamento bibliográfico e geocartográfico de autores que discutem a temática abordada, e a realização de trabalhos de campo com o objetivo de correlacionar os resultados alcançados. Dessa forma, percebeu que o processo de uso e ocupação da área se deve a prática da agricultura de subsistência, do extrativismo vegetal e a pecuária extensiva, vindo a provocar desmatamento, solos desnudos, assoreamento, etc.
\end{abstract}

Palavras-Chaves: Comunidades, agricultura, degradação.

\begin{abstract}
This research seeks to carry out a description of the physical and natural components, and identify the main environmental impacts in Sub-basin of Bilheira stream as a way to subsidize environmental planning. The study area has a land area of 75 square kilometers, fully allocated in the hydrographic system of the river Aracatiaçu where this in turn is inserted in the river basin of the coast. The study area is inserted from the municipal limits of Sobral more precisely in the districts of Taperuaba and Aracatiaçu. The methodology consists of physiographic description of the case of river basins as a unit of study, falls as essential. However, the research was developed through a literature review and geocartográfico of authors who discuss the theme discussed, and conducting field work in order to correlate the results. Thus, realized that the process of use and occupation of the area is due to the practice of subsistence agriculture, plant extraction and extensive cattle ranching, been causing deforestation, bare soil, siltation, etc.
\end{abstract}

Keywords: Communities, Agriculture, Degradation.

\section{INTRODUÇÃO}

Nos últimos decênios se têm percebido que cada vez mais, a sociedade por meio do avanço científico e tecnológico retirou da natureza muito mais daquilo que seu poder natural de reabilitação pode recuperar, potencializando assim a degradação ambiental dos recursos naturais que é uma realidade presenciada tanto em escala macro como em escala micro dos diversos territórios existentes.

Paralelamente, Lima (2012) analisa que decisivamente no fervilhar desses anos passados houve uma grande preocupação com o meio ambiente e com os recursos naturais, no qual Conti e Furlan (2009, p. 86) "Considera como recurso natural todo e qualquer componente da natureza que o homem pode usar em seu benefício." Consequentemente essa preocupação com o meio ambiente

\footnotetext{
${ }^{1}$ Renato Oliveira Barros, Graduando em Geografia, Bolsista de IC - CNPq, Universidade Estadual Vale do Acaraú, Sobral-CE, Brasil

${ }^{2}$ José Marcos Duarte Rodrigues, Mestre em Geografia Física, Universidade Estadual Vale do Acaraú, CE, Brasil

${ }^{3}$ Ernane Cortez Lima, Professor Doutor em Geografia, Universidade Estadual Vale do Acaraú, CE, Brasil
} 
teve uma aplicabilidade e um desenvolvimento significativo das ciências que tratam das questões ambientais.

A maneira como o ser humano usa e ocupa esses ambientes é que vai notabilizar o estado de degradação ou conservação do mesmo. Ressalta-se o pensamento de Cortez (2011) ao ponderar que desde os tempos remotos, o homem buscou da natureza as mais diversas formas de sobrevivência, o diferencial que marcou a relação de equilíbrio ou desequilíbrio dele com a natureza, foi o objetivo de retirada ou apropriação dos bens naturais.

Desta forma, para o seguinte estudo realizou-se um caracterização fisiográfica da paisagem, tendo como unidade de análise a sub-bacia hidrográfica do riacho Bilheira, nessa perspectiva, objetiva-se também realizar um diagnóstico dos impactos ambientais, associados ao uso dos componentes naturais, sendo que a análise inicial do processo histórico de uso e ocupação do solo da área foi primordial para a sua efetivação.

A sub-bacia hidrográfica do riacho Bilheira, está localizada a noroeste do estado do Ceará, situando-se nas cartas matriciais da SUDENE/DGS, SA. 24-X-D-IV (Sobral), SB.24-V-B-I (Santa Quitéria), correspondendo a uma área de $75 \mathrm{Km}^{2}$, pertence ao sistema hidrográfico do rio Aracatiaçu, onde este por sua vez concerne ao sistema hidrográfico da bacia do litoral. A mesma tem sua área inserida totalmente nos limites municipais de Sobral, mais precisamente nos distritos de Taperuaba e Aracatiaçu (Figura 01).
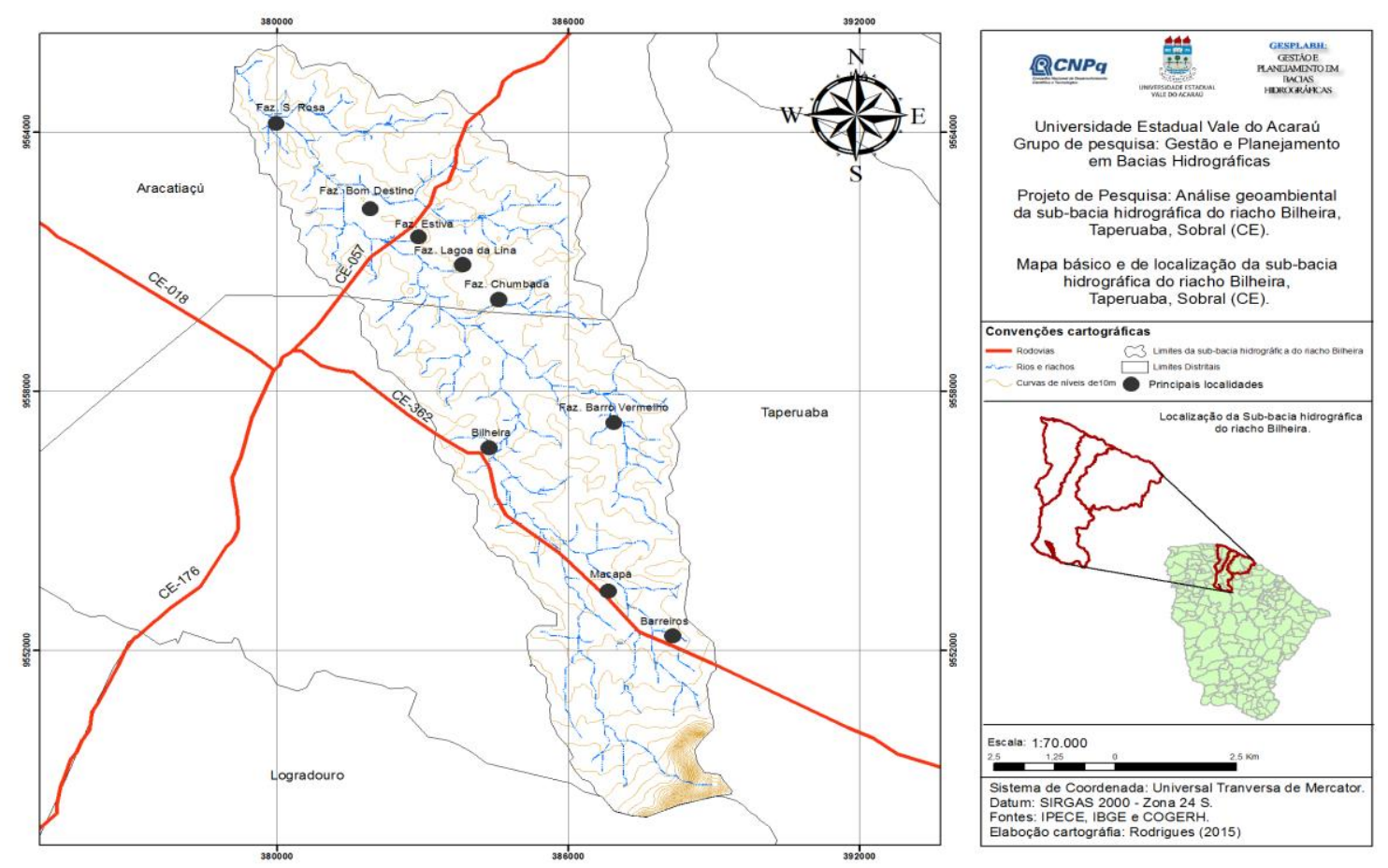

Figura 01: Localização da área de estudo. Fonte: Barros, R.O; Rodrigues, J. M. D, Lima, E. C (2016).

\section{METODOLOGIA}


A metodologia adotada envolve a concepção sistêmica, voltada para análise da paisagem, por meio da descrição e caracterização dos principais fatores fisiográficos da sub-bacia hidrográfica do riacho Bilheira.

O método utilizado fundamenta-se no geoprocessamento através dos Sistemas de Informações Geográficas (SIG) e na análise de produtos de sensoriamento remoto. Onde inicialmente, determinou-se como área de estudo, toda a área inserida no contorno da sub-bacia hidrográfica do riacho Bilheira. Em seguida realizou-se um levantamento de materiais bibliográficos e geocartográfico para auxílio durante os trabalhos de campo, possibilitando o diagnóstico dos componentes físico-naturais (geológico, geomorfológico, climático, pedológico e fitogeográfico), sendo posteriormente levantado o processo de uso e ocupação, diagnosticando os principais impactos ambientais associados ao uso dos recursos naturais.

Os trabalhos de campo ocorreram no decorrer da pesquisa, iniciando em setembro de 2015 (inicio do projeto de pesquisa), abarcando toda a área da sub-bacia hidrográfica do riacho Bilheira, o que possibilitou marcação dos pontos de controle, com o auxílio do GPS (Global Position System) e das cartas topográficas, e também ocorreram os registros fotográficos, possibilitando a averiguação das informações obtidas nos produtos geocartográficos.

Para elaboração do perfil longitudinal, utilizou-se técnicas de geoprocessamento, utilizando imagem de radar SRTM, onde obteve-se o perfil topográfico, fornecendo informações básicas, relacionadas à altitude e a representação do modelado do relevo. Através do arquivo gerado foi, possível sobrepor as demais informações, através do mapeamento temático. As informações acrescentadas referem-se aos componentes físico-naturais.

O processo de uso e ocupação foi empiricamente compreendido através dos trabalhos de campo e por meio de trabalhos de gabinete, utilizando fontes como o Instituto Brasileiro de Geografia e Estatística (IBGE, 2010) e o Instituto de Pesquisa e Estratégia Econômica do Ceará (IPECE, 2013), e também por intermédio dos moradores locais, o que possibilitou diagnosticar, os principais impactos ambientais da área.

\section{RESULTADOS E DISCUSSÕES}

Os resultados foram obtidos a partir da metodologia abordada pautada na análise fisiográfica da paisagem. Portanto, busca-se descrever os componentes físico-naturais, para posteriormente diagnosticar as formas de uso e ocupação, com a finalidade de identificar os principais impactos ambientais.

\subsection{DIAGNÓSTICO DOS COMPONENTES NATURAIS}




\subsubsection{Geologia}

De acordo com o Mapa Geológico do Estado do Ceará, CPRM (2003), em escala de 1:500.000, a área de estudo está submetida sob duas unidades geológicas, são elas: Depósitos Sedimentares Cenozóicos e Complexo Tamboril Santa Quitéria.

Os Depósitos Sedimentares Cenozóicos são compostos por argilas, areias, quartzosas e quartzofeldspáticas, conglomeráticas ou não, cascalhos e argilas orgânicas/fluviais, de granulação grosseira. Esta unidade aparece de forma mais latente no baixo curso onde a gradiente dos canais é baixo, possibilitando o processo de acumulação.

A suíte Intrusiva Tamboril-Santa Quitéria, apresenta-se composta por associação granitomigmatítica, envolvendo granitoides neoproterozóicos, cinzentos e rosados, de granulação variável até termos porfiríticos, gnaissificados ou não, em jazimentos de geometrias e dimensões diversas; ortognaisses migmátíticos, além de rochas calcissilicáticas e anfibolitos. Essa unidade é a mais expressiva na sub-bacia do riacho Bilheira.

\subsubsection{Geomorfologia}

Quanto a geomorfologia, identificou-se três unidades geomorfológicas distintas, a depressão sertaneja, marcada pela primazia de topografias planas ou levemente onduladas, na área de estudos, se configura como a de maior expressividade em termos de extensão territorial. Os inselbergues que na sub-bacia estudada encontra-se no extremo sul, tratando-se do Complexo Granítico do Corrente, apresentando altitudes superiores a $600 \mathrm{~m}$ de altitude.

A Planície Fluvial representam típicas formas de deposição fluvial que oferecem melhores condições de utilização agrícola. Na área abordada a mesma ocupa as áreas subjacentes ao riacho Bilheira e de seus tributários.

\subsubsection{Características Climáticas}

No que concerne as condições climáticas é necessário abraçar o forte apelo de Souza (2000), onde a sub-bacia hidrográfica do riacho Bilheira inserida no estado do Ceará está submetida ao clima semiárido quente que ainda representa o principal condicionante desfavorável ao aproveitamento de seus recursos naturais. As chuvas, além de bastante irregulares, são caracterizadas pela incerteza, com antecipações, retardamentos ou ausências quase absolutas, configurando condições de secas.

Lima (2012) coloca que o principal sistema atmosférico atuantes nas condições climáticas no estado do Ceará é a zona de convergência intertropical (ZCIT), onde acontecem as chuvas que correspondem ao verão-outono do hemisfério sul. O período chuvoso no interior do continente 
configura-se entre os meses de fevereiro a maio, tendo seus índices mais elevados nos meses de março e abril.

\subsubsection{Solos}

Para as classes de solos foram realizados tanto trabalhos de gabinete através da classificação do SIBCS (2006), como através do exame morfológico de perfil realizado em trabalho de campo. Foram identificadas na área averiguada quatro tipos de classes de solos. São elas: Planossolos, Luvissolos, Neossolos flúvicos e Neossolos litólicos associados a afloramentos rochosos.

Os planossolos São solos predominantemente originados de saprolito dos gnaisses e migmatitos do Pré-Cambriano Indiviso e de micaxixtos referidos ao Pré-Cambriano (A), quase sempre influenciados por uma delgada cobertura de material pedimentar ou provenientes de sedimentos argilosos e siltosos pertencentes ao Holoceno (área de várzeas) como ocorre nas várzeas e terraços (LIMA, 2012).

Os luvissolos apresentam o horizonte B textural seguido pelo horizonte A ou E, com argila de alta atividade da parte mais superficial com acumulação nos horizontes sub-superficiais. São solos bem ou imperfeitamente drenados, com pouca profundidade, podendo apresentar pedregosidade superficial.

Os Neossolos flúvicos originam-se de sedimentação fluvial do holoceno, são caracterizados como solos pouco desenvolvidos, apresentando sequencialmente os horizontes A e C. Estes solos variam de moderadamente profundos a muito profundos, de texturas as mais diversas, drenagem comumente imperfeita ou moderada. Em geral são solos de grande potencialidade agrícola.

Os neossolos litólicos São solos pouco evoluídos, sem horizontes B, apresentando o horizonte A seguindo pelo C ou R. É comum encontrar superficialmente pedregosidade ou rochosidades, podendo está vinculada aos afloramentos rochosos.

\subsubsection{Vegetação}

Em relação a classificação da vegetação, optou-se pelo sistema de classificação de Fernandes (1990), onde constatou-se três tipos vegetacionais: a primeira concerne a caatinga arbustiva-subarbustiva ocupa maiores porções da área em estudo comprovada por ocorrência em sua maioria de degradação ambiental.

A segunda se trata da vegetação ribeirinha identificada as margens do riacho Bilheira e de seus tributário. Esse tipo de vegetação encontra-se em solos de aluvião, com maior teor hídrico. As espécies identificadas foram: Oiticica (Licania rígida) e a Ingazeira (Lonchocarpus Sericeus). Porém, devido ao desmatamento, estas espécies sedem lugar a outras espécies características da 
caatinga baixa. Quanto ao estrato arbóreo, ressalta-se que essa vegetação é caracterizada como a de maior porte dentre as caatingas possíveis. $\mathrm{Na}$ área de estudo essa vegetação foi encontrada de forma pontual.

A figura 02, sintetiza a caracterização dos componentes naturais encontrados na área em estudo através do perfil longitudinal na direção N-S.

Perfil Longitudinal da sub-bacia hidrográfica do riacho Bilheira, Taperuaba, Sobral (CE)

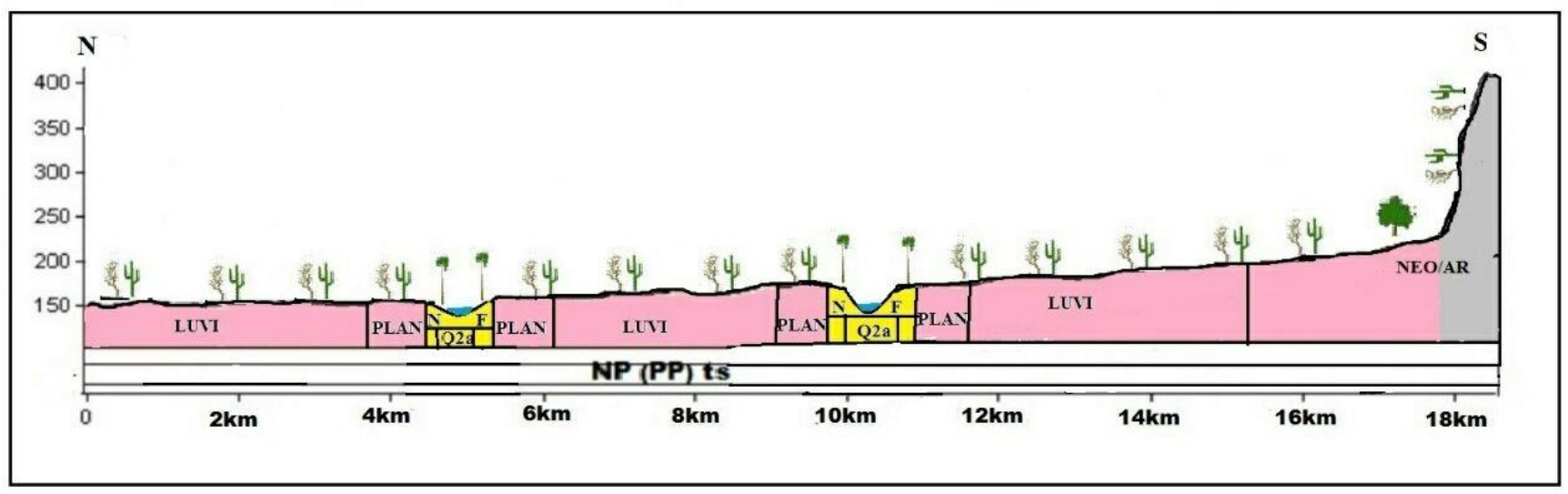

LEGENDA
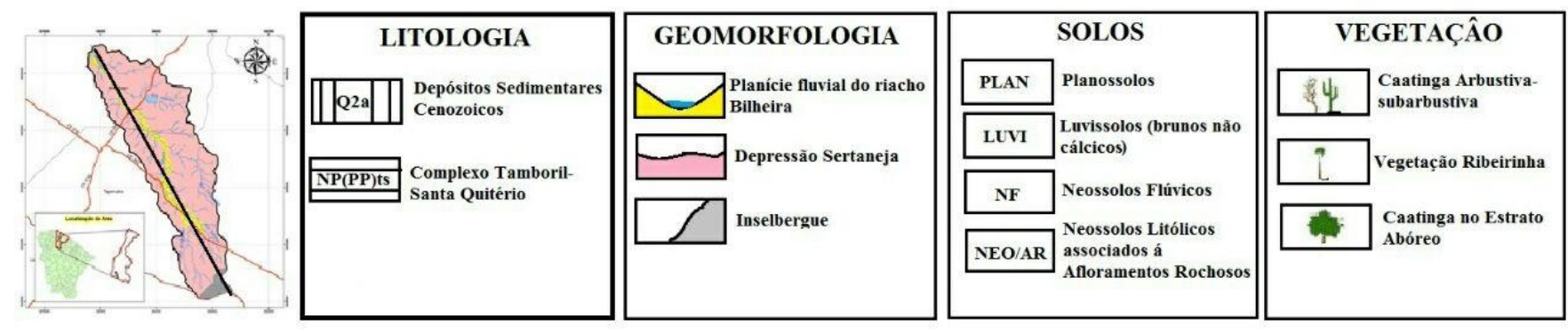

Figura 02: Perfil longitudinal do riacho Bilheira (N-S). Fonte: Barros, R.O; Rodrigues, J. M. D, Lima, E. C (2016).

\subsection{ATIVIDADES SOCIOECONÔMICAS E IMPACTOS AMBIENTAIS ASSOCIADOS}

Na concepção de Pontes (2010), o processo de destruição dos recursos naturais da região Nordeste do Brasil como também de quase toda faixa litorânea brasileira se deu com a ocupação lusitana a partir do século XVI trazendo consigo e instaurando na região dissensões jamais vistas. Sem objetivo de fixação, ainda ficou mais claro o advento dos europeus em terras nacionais o objetivo crucial era expropriar os recursos naturais sem a menor intenção de preservação.

O pensamento descrito acima coaduna com a reflexão de Souza (2000) ao analisar que no Ceará, de modo genérico, as áreas naturais já não possuem suas condições originais. Muitas das características dependem de atividade antrópica intensa e de um processo histórico de ocupação bastante antigo. Rodrigues (2016), afirma que o conhecimento das formas de uso e ocupação da 
terra é de fundamental importância, pois é a partir do manejo inadequado que ocorre a deterioração dos recursos naturais.

Com a averiguação do trabalho de campo, percebeu-se que o uso e ocupação da área deve-se a presença das comunidades que estão alocadas em volta da sub-bacia, constituindo-se principalmente de fazendas que estão distribuídas ao longo da planície fluvial. As residências na grande maioria são de alvenaria, porém ainda encontra-se com facilidade residências de taipa.

As principais atividades socioeconômicas envolvem a prática da agricultura de subsistência, a criação extensiva, extração madeireira, que tem como principais consequências, o desmatamento, a erosão (voçorocamento) e assoreamento, como mostra a figura 03.

A agricultura de subsistência, ainda na atualidade, é desenvolvida por meio de técnicas tradicionais, através do desmatamento, coivaras e logo em seguida a queima da vegetação, isso acaba evidenciando um desequilíbrio ambiental e por ventura acelerando os processos erosivos naquele ecossistema, como também a posteriori assoreando as nascentes dos recursos hídricos.

O extrativismo de madeira também é amplamente constatado na região utilizado para produção de carvão vegetal, como também na revitalização dos apriscos dos animais e na delimitação territorial das propriedades dos moradores através de estacas e arame farpado.

O desmatamento é utilizado como forma mais rápida de preparar o terreno para o cultivo, através da derruba da vegetação para a prática da agricultura de subsistência. O desmatamento em áreas próximas ao dique marginal provoca o assoreamento dos recursos hídricos devido a retirada da mata ciliar provocando o carreamento de sedimentos. O processo de voçorocamento, também está associado a pratica de agricultura de subsistência devido a retirada da vegetação, sendo identificada ravinas e sulcos, nas áreas com relevo plano, nos denominados "roçados".

A criação extensiva na sub-bacia se dá por meio de ovinos, caprinos e bovinos, exercendo influência significativa frente ao uso e ocupação, tornando-se um fator fundamental no povoamento da área. Um outro aspecto da pecuária extensiva, forçada pelos mecanismos de intensificação da exploração dos recursos naturais renováveis, é a geração de uma grande pressão sobre a vegetação nativa, tanto pela eliminação das plantas como pela compactação dos solos, devido ao pisoteio excessivo feito pelo gado. De modo geral, os criadores aumentam o número de bovinos, caprinos e ovinos em limites superiores à capacidade de suporte dos ecossistemas, que é, em geral, muito baixa (OLIVEIRA, 2006). 

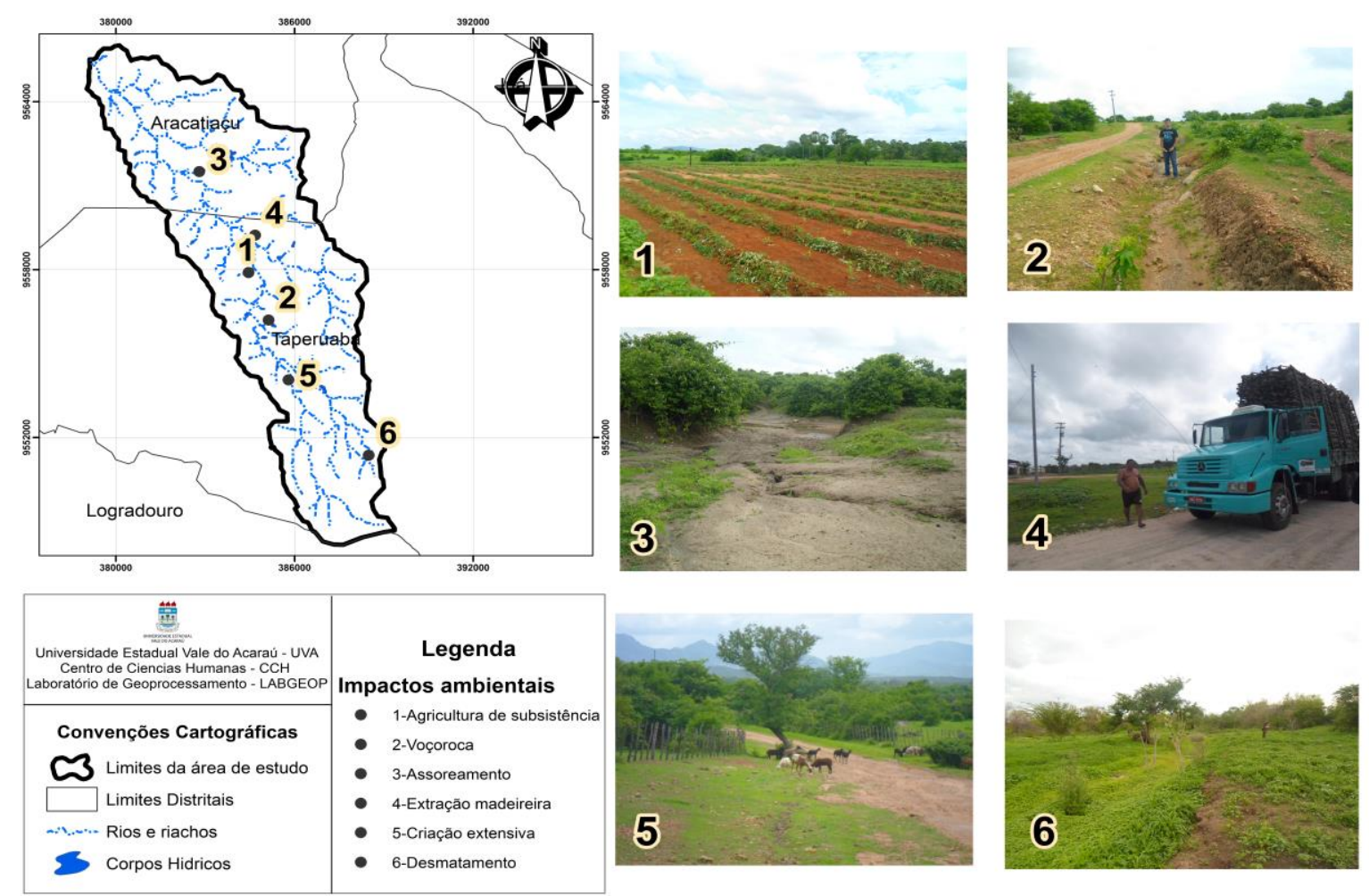

Figura 03: impactos ambientais associados ao uso e ocupação do solo na Sub-bacia hidrográfica do riacho Bilheira.

Destaca-se também, a prática de barramentos em forma de pequenos açudes e barragens que é visivelmente constatada na área. A formação desses pequenos reservatórios visa uma maior acumulação de água para a prática da pesca e dessedentação de animais nos meses de estiagem.

Em relação a mata ciliar a mesma encontra-se bastante descaracterizada tanto na margem direita como na esquerda, o setor da bacia que possui o maior índice de preservação encontra-se no alto curso e se deve inicialmente pela baixa concentração populacional e mais recentemente pela implantação de uma Unidade de Conservação (Refúgio de vida silvestre).

Vale ressaltar, que com as transições paradigmáticas ocorridas no último decênio, se têm notabilizado a ascendência de um novo paradigma contextualizado como "Convivência com o semiárido", e nesse contexto as cisternas de placas do P1MC se notabilizam por garantir a primeira água para as comunidades rurais permitindo assim uma convivência harmoniosa do sertanejo para com o semiárido, e permitindo que o mesmo permaneça em seu habitat. No trabalho de campo, foi bastante certificado esses "pontos brancos" espalhados nas belíssimas paisagens sertanejas ao lado das residências (PONTES, 2010). 


\section{CONSIDERAÇÕES FINAIS}

A pesquisa evidenciou o atual processo de uso e ocupação da sub-bacia hidrográfica do riacho Bilheira. Nesse contexto, as marcas da degradação ambiental e dos recursos naturais se expõem através de condições heterogênicas em que se evidencia o desmatamento indiscriminado, aceleração dos processos erosivos, adelgaçamento dos solos e aparecimento de afloramentos rochosos e a intensificação do assoreamento das nascentes.

Tudo isso está correlacionado, em maior parte, com as práticas agrícolas e com a criação extensiva, uma vez que o homem ainda hoje utiliza técnicas na agricultura como o desmatamento e as queimadas, deixando o solo exposto "propício" para o plantio, porém deixando susceptível a processos erosivos e afloramentos rochosos. Além do mais, como a atividade agrícola é fortemente realizada nas planícies fluviais pelo seu poder de umidade, essa atividade provoca o assoreamento desses ambientes.

Dessa forma, conclui que quase toda a área da sub-bacia do riacho Bilheira está apresentando uma descaracterização acentuada da mata ciliar ao longo das margens do riacho Bilheira e de suas nascentes, como também é vista em todos os setores da mesma, com exceção do alto curso onde possuímos um ambiente relativamente estável, porém temos na margem direita o maior processo de degradação ambiental possivelmente devido ao maior número de comunidades.

\section{REFERÊNCIAS}

CONTI, J. B; FURLAN, S. A. Geoecologia o clima, os solos e a biota. In: ROSS, J. L. S. (Org.).

Geografia do Brasil. São Paulo: Editora da Universidade de São Paulo, 2009. p. 67-208.

CORTEZ, A. T. C. O lugar do homem na natureza. Revista do Departamento de Geografia USP. São Paulo, v. 22, p. 29-44, 2011. Disponível em: < http://www.revistas.usp.br/rdg/article/view/47218/50954>. Acesso em: 01/08/2016.

CPRM. Atlas digital de geologia e recursos minerais do Ceará. Edição 2003 Esc: 1:500.000 CPRM, 2003. 105p.

EMBRAPA. Sistema Brasileiro de Classificação de Solos. $2^{\mathrm{a}}$ ed. Rio de Janeiro, 2006.

FERNANDES, A. Temas fitogeográficos. Fortaleza: Stylus Comunicações, 1990.

IBGE, Instituto Brasileiro de Geografia e Estatística. Censo demográfico 2010. Disponível em: <http://www.ibge.gov.br>. Acesso em: 01/08/2016.

IPECE. Anuário Estatístico do Ceará. 2013. Disponível em: <http://www2.ipece.ce.gov.br/publicacoes/anuario/anuario2013/demografia/populacao.htm>. Acesso em: 01/08/2016. 
LIMA, E C. Planejamento ambiental como subsídio para gestão ambiental da bacia de drenagem do açude Paulo Sarasate Varjota - Ceará. Fortaleza, 2012. 201f. Tese (Doutorado em geografia) - Universidade Federal do Ceará, UFC, 2012.

OLIVEIRA, V. P. V. A problemática da degradação dos recursos naturais no domínio dos sertões secos do estado do Ceará - Brasil. In: SILVA, J. B. et al (Org.). Litoral e Sertão: natureza e sociedade no Nordeste brasileiro. Fortaleza: Expressão Gráfica, 2006. p. 187-200.

PONTES, Emilio Tarlis Mendes. Transições paradigmáticas, do combate à seca à convivência com o semiárido. O caso do Programa Um Milhão de Cisternas no município de Afogados da Ingazeira. Recife: EDUFPE, 2010.

RODRIGUES, J M D. Análise dos sistemas ambientais da Sub-bacia hidrográfica do rio Bom Jesus, Taperuaba, Ceará, Brasil. 2016. 181f. Dissertação (Mestrado em Geografia). Universidade Estadual Vale do Acaraú. Sobral. 2016.

SOUZA, M, J, N. Bases naturais e esboço do zoneamento geoambiental do estado do Ceará. In: LIMA, Luiz C; MORAIS, Jáder O. SOUZA, M. J. Nogueira de. (Org.). Compartimentação territorial e gestão regional do Ceará. Fortaleza: Editora FUNECE, 2000. p. 5-104.

\section{AGRADECIMENTOS}

Á Universidade Estadual Vale do Acaraú, ao Laboratório de Geoprocessamento e ao CNPq pela concessão e fomento da bolsa.

Recebido em: 14/08/2016

Aceito para publicação em: 01/10/2016 